\title{
Fabián Gandini y la est(ética) de la fisura
}

\author{
Juan Ignacio Vallejos \\ Consejo Nacional de Investigaciones Científicas y Técnicas - Instituto \\ de Altos Estudios Sociales - Universidad Nacional de San Martín
}

"Se modifica la forma de la madera, por ejemplo, cuando con ella se hace una mesa.

No obstante, la mesa sigue siendo madera, una cosa ordinaria, sensible.

Pero no bien entra en escena como mercancía, se trasmuta en cosa sensorialmente suprasensible.

No sólo se mantiene tiesa apoyando sus patas en el suelo, sino que se pone de cabeza frente a todas las demás mercancías y de su testa de palo brotan quimeras mucho más caprichosas que si, por libre determinación, se lanzara a bailar".

Karl Marx

El carácter fetichista de la mercancía y su secreto

Dos intérpretes entran en escena, cada uno de ellos se ubica en un lugar preciso, actúan como operarios en una fábrica atentos al engranaje de sus acciones. El primero toma una larga tela roja y se cubre con ella extendiendo sus brazos por encima de los hombros. La imagen introduce suspenso: un actor que se esconde detrás de un telón en miniatura. El otro saca un grabador digital portátil de su bolsillo y comienza a grabar el sonido que produce el roce del micrófono en su contacto con la tela. Es un sonido íntimo totalmente inaudible para todos nosotros, espectadores. Entra una intérprete más; se esconde detrás del telón 
rojo. Luego, ambos caminan hacia el otro extremo del escenario en donde están expuestas una computadora portátil, un proyector, una consola de sonido y un amplificador conectado a dos parlantes. Él ahora graba el sonido de un soplido. Entra una cuarta intérprete. Él graba el sonido de sus pasos y el que se produce al desplegar una alfombra de plástico redonda en el suelo. Estamos en el otro extremo del escenario. La cuarta intérprete se detiene con una bolsa de tierra al borde de la alfombra. Se proyecta hacia el fondo de la escena un rectángulo de luz, una suerte de marco para un cuadro imaginario que recorta la pared. Una quinta intérprete entra, se instala en el medio de la escena y comienza una acción escultórica: sostiene con una mano una "zapatilla" de enchufes, con la otra una lamparita y parece intentar unirlas imposiblemente. La imagen introduce un elemento de tensión que se agrega a las otras acciones que componen la escena. El intérprete que sostiene el grabador se acerca a la computadora, descarga el sonido grabado y arma con él un loop que comienza a escucharse por los parlantes. Luego, reemplaza al intérprete que sostiene la tela roja y se coloca detrás de ella. Este último intérprete camina hacia el otro extremo del escenario y sostiene una lámpara apagada que se dirige al centro del espacio. En el muro del fondo se proyecta la siguiente frase: "La cantidad de horas humanas que las cosas llevan de forma oculta generan infinitas presencias invisibles".

\section{LA PRESENCIA INVISIBLE}

Según Fabián Gandini, su obra En la boca de la tormenta, parte de una propuesta escénica simple: potenciar la presencia de los objetos. Su idea al comienzo "era trabajar con la cosa - con la materia y la luz-y que los cuerpos actúen como un dispositivo más para que esa 'cosa' se potencie". ${ }^{1}$ De este modo, para el coreógrafo, lo que hace el cuerpo del intérprete en escena es simplemente "tensar" el tiempo de la "cosa". Su trabajo es el de ser un tensor o, más bien, un extensor del objeto ya que según Gandini, a través de este procedimiento se logra "alterar la materia", estirándola como a un cuero. El cuerpo actúa como un factor del movimiento del objeto: "la materia se altera desde el lugar del que ve porque el cuerpo se interpone". ${ }^{2}$

Desde sus inicios, el trabajo estuvo enmarcado por los límites de este procedimiento. En los primeros ensayos Gandini trabajó con una sola intérprete en escena y tres objetos: una silla, un cable y una lamparita. El cuerpo buscaba hacer las veces de un artefacto que encuadraba la materia y la subvertía. En la

${ }^{1}$ Diomedi 2015: sin paginar.

2 Diomedi 2015: sin paginar. 
boca de la tormenta se estrena en septiembre de 2015 y emerge como la contracara de su creación inmediatamente previa: Cartas a mi querido espectador de 2013. En esa obra, Gandini había intentado trabajar desde algo que él define como el "mínimo nivel de representación". La ficción se sostenía a partir de la presencia de dos intérpretes en un espacio indeterminado sin butacas ni luces de escena, cuya principal acción era leer cartas escritas en hojas de papel.

Luego de esa experiencia, en la que el coreógrafo afianzó su proyecto estético de construir ficción a partir de los recursos más elementales, se lanzó a la búsqueda de cierto imaginario que intentara potenciar esa "poética elemental". La nueva obra fue concebida, en cierto modo, como ambiciosa, tiene una impronta visual muy elaborada y superpone numerosos dispositivos sonoros, fílmicos y de movimiento. Sin embargo, enseguida advertimos que se trata de una ambición condicionada por la exposición: exposición de la precariedad de los recursos pero sobre todo de su fragilidad y de la fragilidad de los intérpretes bailarines que se exponen crudamente a la mirada del espectador desprovistos de un virtuosismo técnico tradicional.

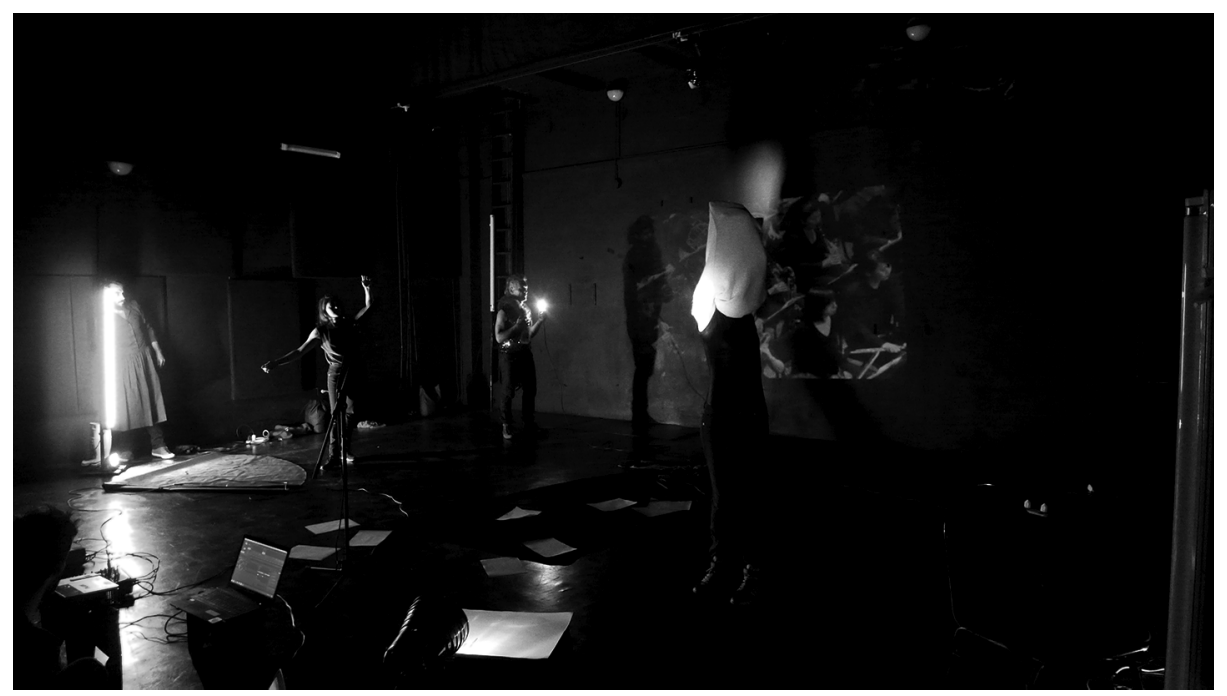

[Fig. 1. Fabián Gandini, Obra "En la boca de la tormenta”. Fotógrafo: Jorge Leiva. Año 2015.]

Volvamos a la frase que se proyecta al comienzo de la obra: "La cantidad de horas humanas que las cosas llevan de forma oculta generan infinitas presencias invisibles". La frase expresa el sentido inicial del proceso creativo: potenciar la presencia de los objetos visibilizando las "horas humanas" que llevan 
ocultas. En su libro El Capital, Karl Marx introduce el concepto de fetichismo de la mercancía en los siguientes términos:

Lo misterioso de la forma mercantil consiste sencillamente, pues, en que la misma refleja ante los hombres el carácter social de su propio trabajo como caracteres objetivos inherentes a los productos del trabajo, como propiedades sociales naturales de dichas cosas, y, por ende, en que también refleja la relación social que media entre los productores y el trabajo global, como una relación social entre los objetos, existente al margen de los productores. ${ }^{3}$

Según el análisis clásico de Marx, el fetichismo de la mercancía conduce a una sobreestimación teórica del proceso de intercambio por sobre el proceso de producción, algo que se condice con la práctica de un "culto al mercado". Mi idea en este artículo no es discutir teóricamente este concepto sino explorar su utilidad como herramienta explicativa en relación a la obra de Fabián Gandini y a las condiciones de producción artística en el campo de la danza independiente en Buenos Aires. La idea de fetichismo constituye un pilar para la interpretación marxista del sistema capitalista y para su teoría de la alienación. Sin embargo, pensemos por un momento que la complejidad de ese término podría resumirse en la siguiente frase de Gandini: "las cosas encierran horas humanas, son el vector de una presencia".

Siguiendo esta lógica interpretativa, podemos pensar que la acción escénica que describimos al comienzo de este texto: grabar el "sonido íntimo" de las cosas para luego ofrecerlo a los espectadores como ambiente sonoro de la obra, representa un intento por capturar la voz oculta de la materia y sumergirnos en su mundo. Así, podríamos afirmar en un primer momento que el proyecto político que defiende En la boca de la tormenta es el de "desfetichizar" los diferentes elementos, dispositivos y relaciones sociales de la cual ella misma es el emergente. Es un intento por visibilizar su propio "trabajo oculto", sus "horas humanas". Así, se instala un mecanismo en escena que es el de "humanizar la cosa", tratándola como a un intérprete más, como a la encarnación de una presencia invisible. Este presupuesto cuya función principal es la de actuar como un disparador de acciones escénicas, posiciona a la obra, al mismo tiempo, en un plano político de visibilización de "lo real" en la producción artística.

En su análisis de la violencia sistémica del capitalismo financiero actual, Slavoj Žižek introduce una interpretación de la teoría marxista inspirada en la diferencia lacaniana entre la "realidad" y "lo real". Allí,

la 'realidad' es [definida como] la realidad social de las personas concretas implicadas en la interacción y en los procesos productivos, mientras

\footnotetext{
${ }^{3}$ Marx 2007 [1867]: 88.
} 
que lo 'real' es [definido como] la lógica espectral, inexorable y 'abstracta' del capital que determina lo que ocurre en la realidad social. ${ }^{4}$

La eficacia del análisis marxista no está en reducir el "culto al mercado" a la realidad social que lo determina sino en entender que esa realidad social de la producción material y de la interacción humana no puede aislarse de esa otra dimensión intangible. En este sentido, Žižek afirma que

la forma más elevada de ideología no consiste en estar atrapados en lo espectral de la ideología, olvidando su fundamento en las personas reales y en sus relaciones, sino precisamente en pasar por alto lo real de esta espectralidad y pretender dirigirse directamente a las 'personas reales con sus preocupaciones reales'. ${ }^{5}$

La "desfetichización" de las "cosas", propuesta por Gandini, no implica reducirlas a la realidad de su producción material. No se trata de representar la realidad social y económica que existe por detrás del objeto artístico sino de exponer la espectralidad de "lo real" en la obra, teniendo en cuenta que esta espectralidad es inherente a su propia condición ficcional. Las materias corporal y objetual en escena exponen de este modo la encarnación reflexiva de esa espectralidad "real".

\section{LA OBRA-FETICHE}

Conocí a Fabián Gandini en el año 2013, nos presentó Susana Tambutti. Yo había defendido una tesis sobre el ballet pantomima y las Cartas sobre la danza y los ballets de Jean-Georges Noverre y Fabián Gandini acababa de presentar su obra Cartas a mi querido espectador. Susana nos propuso trabajar en una obra en colaboración pero finalmente yo no pude sumarme por falta de tiempo. Sin embargo, nos hicimos amigos rápidamente. En 2014, Fabián comenzó con los ensayos de su nueva obra en su casa junto a los intérpretes Paula Almirón, Dalilah Spritz y German "Patán" Cunese, a quienes se sumó unos meses más tarde Sofía Grenada. Comencé asistiendo a algunos ensayos. Luego, en 2015, se necesitó un espacio más adecuado para el trabajo y Fabián solicitó una residencia en el Centro Cultural Sábato de la Facultad de Ciencias Económicas de la Universidad de Buenos Aires. El subsidio otorgado por PRODANZA para la realización de la obra fue el equivalente en pesos de unos 4000 dólares y no era suficiente para alquilar una sala de ensayo. La condición que se nos propuso para acceder al espacio en el Sábato era hacer una convocatoria abierta para que

\footnotetext{
${ }^{4}$ ŽıžEK 2009 [2008]: 23-24.

5 ŽıžEK 2009 [2008]: 24.
} 
estudiantes y artistas pudieran formar parte de un grupo de estudios que dialogara con el trabajo de la obra. Fabián me pidió que coordinara ese grupo y, por esa razón, logré tener una cercanía bastante importante con el proceso de montaje, colaborando desde mi lugar como teórico. La experiencia me permitió observar desde adentro las condiciones en las que se produce una obra de danza contemporánea independiente en Buenos Aires, algo que influyó de manera determinante mi percepción del trabajo artístico.

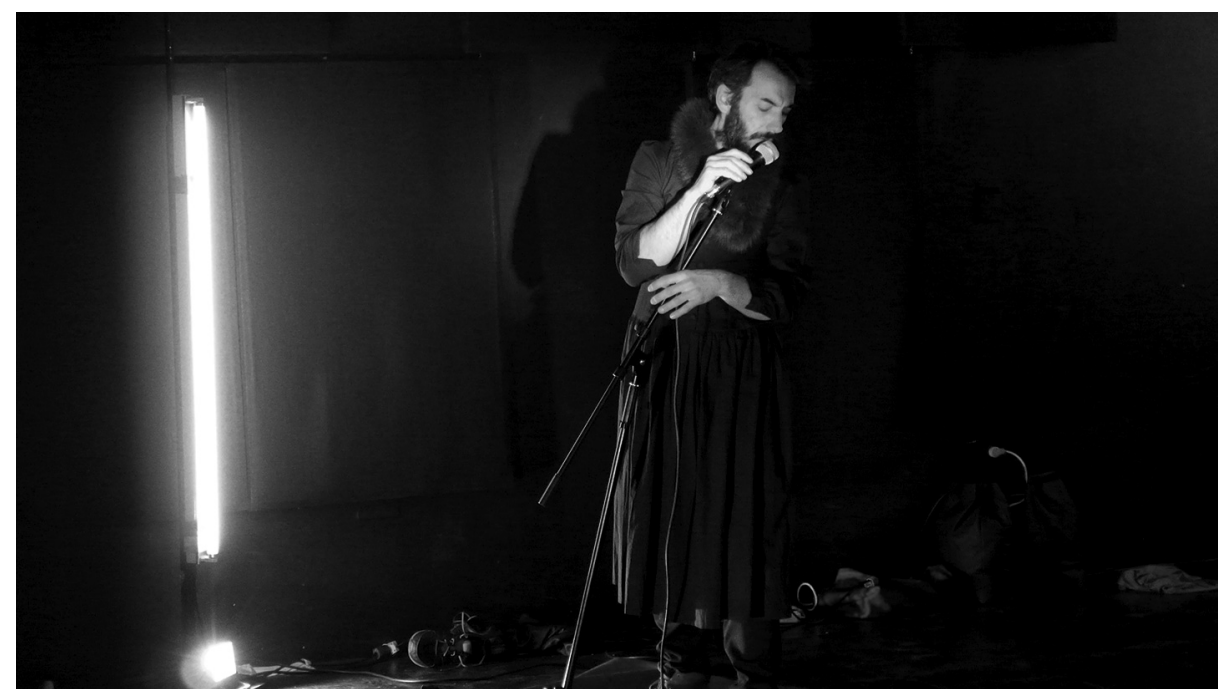

[Fig. 2. Fabián Gandini, Obra "En la boca de la tormenta”. Fotógrafo: Jorge Leiva. Año 2015.]

Gandini concibe su trabajo como una superposición de capas que terminan formando una densidad poética por acumulación. En su obra no existe una narrativa diacrónica. Se trata más bien de una escritura sincrónica que adquiere la forma de un palimpsesto. A los objetos se les suma un texto, una imagen proyectada, una canción, un movimiento, un cuerpo. En este procedimiento, se va introduciendo, a través de frases, audios de ensayos, testimonios de los intérpretes y escenas que se repiten incorporando leves modificaciones, un registro documental ficcionalizado del montaje de la obra. ${ }^{6} \mathrm{El}$ archivo expuesto constituye una superficie que la transforma en un dispositivo de representación de su propio pasado, de su historia y de su condición material como mercancía. El proyecto de "desfetichización" de las "cosas" que propone la pieza se

\footnotetext{
${ }^{6}$ Esta idea está inspirada en el trabajo de investigación doctoral de Leslie Cassagne acerca de la materia documental en las formas coreográficas contemporáneas, a quien agradezco sus observaciones sobre este texto.
} 
invierte y aparece un segundo plano de análisis que es el de observar a la misma obra como un fetiche. Este segundo plano puede articularse con la definición tradicional del concepto de fetiche: el de ser un objeto de culto al que se le atribuyen poderes sobrenaturales. Así, podemos imaginar que la obra comienza a tomar vida, a independizarse, a generar lógicas autárquicas, pasa a ser una máquina que se autoregula, que posee un discurso propio y una autoconsciencia de su propio proceso.

Unos días antes del estreno, el periodista Maximiliano Diomedi hizo una entrevista a Fabián Gandini y a los intérpretes de la obra, en la que también participé. Allí Gandini sostenía:

No es que agarramos el marco, lo conceptual, esta moda o lo que sea. [...] Hay algo social que para mí... Quiero decir, yo estoy creando una obra y por suerte apareció un subsidio [...], pero en realidad yo todavía no tengo un peso. La plata que fue saliendo es porque yo ponía o ellas ponían. Y ese discurso está en la obra sin que quede por delante, sin hacer un panfleto. Entonces toda esa estructura de la lamparita, la silla y ella, hasta el mismo proceder tiene por detrás la potencia o el corazón de ese discurso. Es una precariedad que genera poética. ${ }^{7}$

La idea de concebir la precariedad como potencia está presente en muchos discursos artísticos actuales. Algunos actores del medio elogian de manera un poco cínica la "vitalidad y frescura" de los artistas pobres de países pobres que trabajan esforzadamente por "su amor al arte" y otros entienden a la precariedad como a un límite que genera una verdadera potencia artística. En este último sentido, Paula Almirón sostenía durante la entrevista que la precariedad de la obra escondía una postura ética ya que planteaba la pregunta de: “¿Qué define una cosa, a qué uno le da valor? Uno en el escenario y uno en la sociedad como individuo". La obra planteada en esos términos, expresa una est(ética) de lo esencial que se constituye como crítica de la superficialidad de la sociedad de consumo que nos atraviesa. Para Almirón, el recorte que se establece en la escena busca interpelar al espectador, no es ingenuo. La fragilidad de la puesta y su precariedad establece un planteo ético: ¿Qué condiciones materiales y simbólicas necesita un espectador para convalidar con su mirada una ficción escénica?

Por su parte, Gandini afirmaba que efectivamente había una voluntad explícita de hacer visible el "artificio del dispositivo", su precariedad, su fragilidad, para evidenciar así las condiciones específicas de producción de la obra. En este sentido, podría decirse que el autor dialoga con las ideas propuestas por Bojana Kunst ${ }^{9}$ acerca de la visibilidad del trabajo artístico, ya que, según lo que

\footnotetext{
7 DiOMEDI 2015: sin paginar.

${ }^{8}$ Diomedi 2015: sin paginar.

${ }^{9}$ Kunst 2015: 153.
} 
plantea Kunst, lo político en el arte contemporáneo debería articularse a través de la visibilización de las condiciones de explotación específicas del campo artístico y no a través de una representación metafórica de la explotación humana. La precariedad del artificio artístico expuesto en la obra no es una metáfora que remite a un elemento externo, no es un discurso que enarbola un alegato en contra de la explotación, es la exhibición de algo que forma parte de la misma subjetividad de los artistas, algo intrínseco a la misma de la obra, por eso es una precariedad que genera poética porque es un elemento constitutivo de su práctica artística. La obra exhibe la precariedad como una condición "real", en términos de Žižek, del arte y de los artistas de la ciudad de Buenos Aires. La precariedad puede leerse como un espectro omnipresente y determinante, no sólo de las condiciones materiales de producción sino también del valor simbólico de la obra y del trabajo de los artistas en nuestra cultura.

De ahí accedemos a un nuevo aspecto del fetichismo de la obra que se relaciona, en cierto modo, con el colonialismo estético expresado en lo que Eleonora Fabião define como una "paranoiac mimicry [imitación paranoica]". ${ }^{10}$ Los artistas latinoamericanos independientes se sienten en muchos casos obligados a montar obras con un nivel de producción similar al de los países centrales, algo que debido al bajo financiamiento del que disponen en la gran mayoría de los casos se vuelve un objetivo muy difícil de alcanzar. El deseo de ser aceptados por los medios hegemónicos europeos o norteamericanos hace que en muchos casos persigan modelos estéticos ajenos a la realidad cultural y material en la que viven. Esto de por sí no es algo cuestionable, el problema son las consecuencias que produce en la vida de los artistas implicados. Uno de los temas comunes a la hora de producir una obra de danza contemporánea independiente en Buenos Aires es que la gran mayoría del dinero de la producción sea usado para pagar vestuario, iluminación, escenografía, salas de ensayo o artefactos electrónicos en lugar de horas de trabajo de los intérpretes. Esto es algo que no sólo influye negativamente en las condiciones materiales de vida de los intérpretes sino que relega simbólicamente su trabajo artístico a un lugar de inferioridad. Por esta razón, Gandini afirmaba en la entrevista que si pudiera acceder a un mayor financiamiento intentaría hacer que los interpretes reciban más dinero ya que "no puede ser que la obra gane más que [ellos], es ilógico"."11

10 FABĨ̃o 2010: 109.

11 Diomedi 2015: sin paginar. 


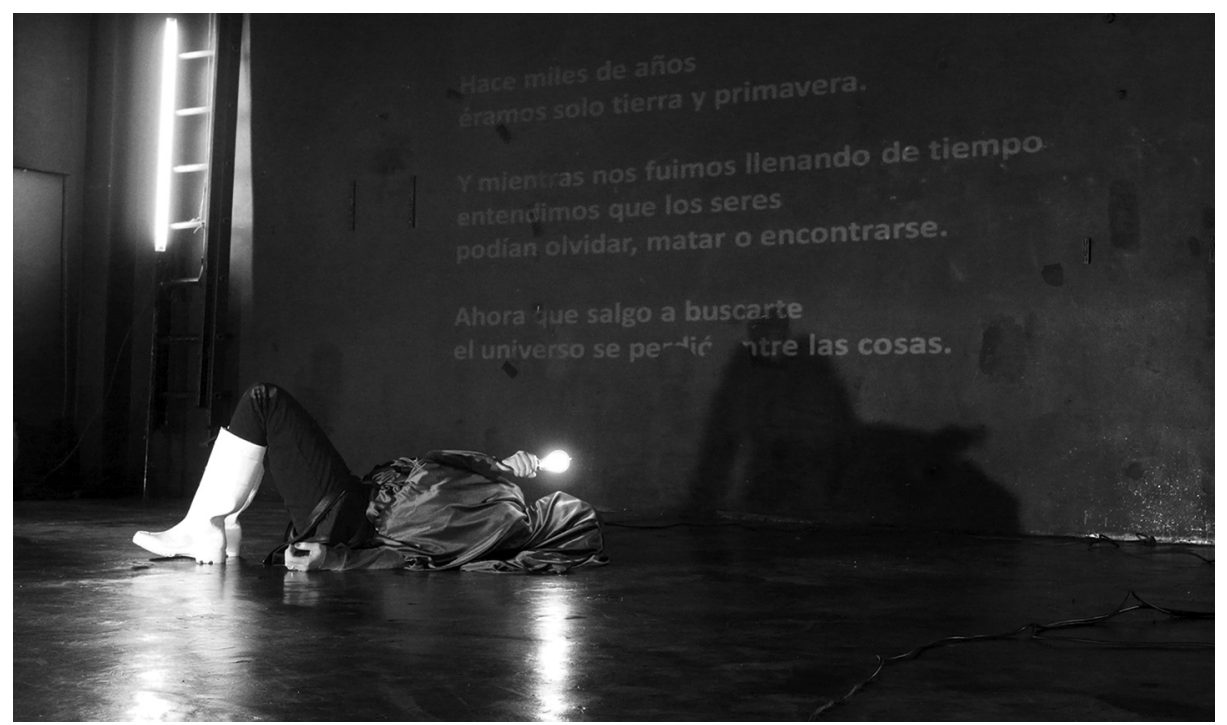

[Fig. 3. Fabián Gandini, Obra "En la boca de la tormenta". Fotógrafo: Jorge Leiva. Año 2015.]

Muchos sociólogos al analizar el comportamiento de la burguesía argentina afirman que Argentina es un país de empresarios ricos y empresas pobres. En el terreno de las artes escénicas esta relación se invierte, Argentina suele ser un país de obras ricas y artistas pobres. Esta quizás sea otra forma de entender a la obra como fetiche: la obra rica que se emancipa del artista que la produce para imitar estéticas europeas. El fundamento racional de este fenómeno a nivel individual es la lógica del emprendedor empresarial, una cultura que no ha logrado instalarse en la burguesía argentina pero sí en el campo artístico. Los artistas invierten todo su dinero en sus obras a la espera de que un día el éxito les devuelva con creces el monto invertido. Así, la obra se transforma en un artefacto que coloniza la vida del creador. La obra no es trabajo, la obra deviene la vida misma del artista. La indiferenciación postfordista entre trabajo y vida se transforma en Buenos Aires en una indiferenciación entre obra-fetiche y artista paranoico.

\section{LA ÉTICA DE LA PRESENCIA}

Un momento importante en la carrera de Fabián Gandini fue su participación en el XIX Festival Panorama de Brasil en 2010 con su obra Pieza para pequeño efecto. Allí tomó contacto por primera vez con artistas europeos como Xavier 
Le Roy u Olga Mesa. El hecho de haber sido seleccionado para participar de ese festival en igualdad de condiciones con esos artistas funcionó como una suerte de legitimación personal de su proyecto estético y le dio la certeza necesaria para continuar. Sin embargo, al hablar de esta experiencia en la entrevista previa a la presentación de En la boca de la tormenta, Gandini dirigió su atención hacia otro tema: el de la búsqueda del éxito artístico - es decir, ser invitado a festivales importantes, viajar por el mundo, ganar dinero-y el modo en que eso condiciona el cuerpo presente del intérprete y su sensibilidad escénica:

no sé si... quizás habría querido. Porque uno piensa que "el lugar" es el Festival Internacional, qué se yo, no sé. O te corrés y decís que no te importa. Aceptar eso hace que uno diga: ,Es esto y desde acá construyo'. Y ahí es cuando logra entidad un cuerpo o cuando yo lo logré. ¿Viste cuando lo soltás y decís: ,No sé si quiero que me quieran'? Y entonces sos esa cosa. Uno está siempre queriendo eso, pero hay algo que podés sol$\operatorname{tar}$ un poco. ${ }^{12}$

Ese "soltar un poco" constituye para Gandini una condición indispensable para que el intérprete potencie su presencia escénica. Desde esa lógica, pensar una obra como obra de danza supone "exponer" el cuerpo del intérprete en escena. Es a partir de esa exposición que el intérprete "hace la obra". Esa es la razón por la cual, según él, en sus trabajos se "ve" al intérprete "como persona", aparecen los cuerpos con nombres, con historias, con sensibilidades, sin la necesidad de que eso sea remarcado. Esta exposición hace al planteo social y político de su proyecto estético. Las condiciones de vida del cuerpo forman parte de la propuesta escénica. Para Gandini, existe una contraposición entre el deseo por parte del intérprete de "triunfar" en el mercado de la danza a nivel internacional y su presencia escénica, su capacidad de "estar" en la escena. Se trata en última medida de superar la paranoia que impone a los intérpretes de países periféricos como Argentina el hecho de que los centros artísticos que otorgan legitimidad se encuentren tan alejados de su realidad y sean tan pocos quienes puedan acceder a ellos.

Quizás sea necesario agregar que las principales instituciones oficiales de la danza contemporánea en Argentina como el Teatro General San Martín promueven, aún hoy en día, una estética neoclásica. El gusto de una gran parte de los críticos de danza que escriben en los medios gráficos es neoclásico y valoran fundamentalmente el virtuosismo técnico de los intérpretes. En este sentido, las obras de danza conceptual son observadas muchas veces como "copias ilegítimas" de la no-danza europea. Son obras a las que no se les concede el derecho a su propia identidad estética. Presentar una obra como En la boca de la

12 Diomedi 2015: sin paginar. 
tormenta que tiene una duración de más de dos horas y que no posee un aparato discursivo que la sostenga, ni un apoyo claro por parte de la crítica implica sin lugar a dudas una exposición enorme para el coreógrafo y para los intérpretes que la realizan. La fragilidad de los movimientos y del montaje se condice con la frágil legitimidad a la que está sometida.

\section{LA FISURA DEL TIEMPO}

En un artículo reciente Gerald Siegmund manifiesta un problema que encuentra de manera recurrente hoy en día en su trabajo como docente, esto es "student's impulse not to move at all anymore, since according to their understanding, any kind of movement can be exploited by creative capitalism [el impulso de los estudiantes de no moverse en lo absoluto, ya que según su interpretación, cualquier tipo de movimiento puede ser explotado por el capitalismo creativo]". ${ }^{13}$ La quietud o la lentitud de acciones como forma de resistencia o desobediencia política ha ganado una considerable aceptación este último tiempo. Por ejemplo, Bojana Kunst ${ }^{14}$ afirma que el trabajo sobre la duración del movimiento puede tener una carga culturalmente subversiva porque visibiliza el modo en que nuestra percepción acelerada del tiempo está construida socialmente y condicionada económicamente. En ese sentido, en el último capítulo de su libro Artists at work propone como consigna de desobediencia en defensa del arte: "do less, precisely when confronted with the demand to do more [haz menos, precisamente cuando te confrontes con la demanda de hacer más]". ${ }^{15} \mathrm{En}$ su famoso libro Exhausting Dance, André Lepecki también cuestiona la definición de la danza como movimiento y la connotación implícitamente positiva de esta definición. ${ }^{16}$ En ese sentido, retoma el concepto de "still-act [acto detenido]" de la antropóloga Nadia Seremetakis y sostiene que "the still acts because it interrogates economies of time, because it reveals the possibility of one's agency within controlling regimes of capital, subjectivity, labor, and mobility [el detenimiento actúa porque interroga las economías del tiempo, porque revela la posibilidad de una acción individual en medio de los regímenes del capital, de la subjetividad, del trabajo y de la movilidad]". ${ }^{17}$

El trabajo escénico de Fabián Gandini también está fuertemente marcado por la lentitud e incluso por la quietud del cuerpo en escena. En su caso, él no la

\footnotetext{
13 Siegmund 2016: 27.

14 KUNST 2015: 131.

15 KUNST 2015: 192.

16 LEPECKI 2006: 12.

17 LEPECKI 2006: 15.
} 
asocia con un acto de resistencia sino con una capacidad del intérprete de "estar" en la escena, de exponerse como persona ante el público. En su universo, la presencia se relaciona, de este modo, con la lentitud, con el tiempo de la acción y con un abandono del deseo, para el caso, del deseo de sobresalir en el mercado artístico internacional. La lentitud no expresa necesariamente desobediencia o resistencia, no hay un razonamiento estratégico que la sostenga. La lentitud es el vehículo para una fragilización afectiva. En última medida, su poética de la lentitud se apoya en una ética artística.

Según el análisis de James Laidlaw, a partir de los escritos de Michel Foucault puede establecerse una diferencia entre moral y ética. ${ }^{18} \mathrm{Si}$ los códigos morales suponen un conjunto de reglas y costumbres promovidas y albergadas por instituciones como la escuela, la familia o la iglesia, frente a las cuales un individuo puede oponer resistencia o simplemente obedecer, la ética implica un procedimiento a partir de la cual los individuos se toman a sí mismos como objeto de reflexión y adoptan prácticas tendientes a moldear su propia conducta y transformarse. La ética implica una toma de posición individual en el campo de la moral.

En su trabajo artístico, Fabián Gandini articula un planteo ético. Creo que su mayor influencia en este sentido es su religión: practica el budismo desde hace más de diez años. Hay una clara relación entre su modo de pensar la presencia en escena y el abandono del deseo, y la práctica de la meditación como acto de presencia consciente. Su obra habla de un desgarro de la existencia pero no permanece anclada en esa desazón, propone una salida que se articula con lo afectivo y con una limitación del sufrimiento. La lentitud busca establecer un mayor nivel de tensión en el tiempo, en sus palabras, es como si se "ensanchara la línea del tiempo para meter más cosas". El objetivo de alargar una acción y lograr que se dilate en el tiempo es habilitar nuevas posibilidades de lectura sensible. La alteración del tiempo evidencia la presencia del cuerpo y lo fragiliza ofreciendo al espectador un encuentro afectivo. De ahí surge la idea de pensar al tiempo como a un artilugio que permite abrir fisuras en la representación. La dilatación del tiempo de la acción En la boca de la tormenta abre $f$ suras a través de las cuales queda exhibido "lo real" de la ficción escénica, su precariedad intrínseca, su fragilidad interpretativa pero también la potencia del encuentro afectivo al que podemos acudir.

${ }^{18}$ LAIDLAW 2014: 29. Citado por RUPRECHT 2017: 5. 


\section{Bibliografía}

Diomedi 2015 - M. Diomedi, Trabajo con la fisura. Entrevista con Fabián Gandini, director de En la boca de la tormenta, "Patología cultural", blog, 22 de octubre de 2015, http://patologiacultural.blogspot.com. ar/2015/10/trabajo-con-la-fisura-entrevista-con.html, Visitado por última vez el 1 de septiembre de 2017.

FABĩ̃o 2010 - E. Fabião, On Precariousness and Performance: 7 Actions for Rio de Janeiro, "Women \& Performance: a journal of feminist theory", n. 20, (1) 2010, pp. 101-111.

Kunst 2015 - B. Kunst, Artist at Work, Proximity of Art and Capitalism, Winchester-Washington 2015.

LAIDLAW 2014 - J. Laidlaw, The Undefined Work of Freedom: Foucault's Genealogy and the Anthropology of Ethics, en: J. Faubion (ed.), Foucault Now: Current Perspectives in Foucault Studies, Cambridge 2014, pp. 23-37.

LEPECKI 2006 - A. Lepecki, Exhausting Dance. Performance and the politics of movement, Nueva York-Londres 2006.

Marx 2008 [1867] - K. Marx, El Capital. Tomo 1, Vol. 1., Buenos Aires-Madrid 2008. [1867]

RUPRECHT 2017 - L. Ruprecht, Introduction: Towards an ethics of gesture, "Performance Philosophy", vol. 3 (1), 2017, pp. 4-22.

Siegmund 2016 - G. Siegmund, Mobilization, Force, and the Politics of Transformation, "Dance Research Journal", n.48, (3) 2016, pp. 27-32.

ŽıžEK 2009 [2008] - S. Žižek, Sobre la violencia. Seis reflexiones marginales, trad. A. J. Antón Fernández, Buenos Aires 2009. [Violence, 2008] 


\section{Summary}

\section{Fabian Gandini and the est(ethics) of the fissure}

During 2015, I collaborated with the Argentine choreographer Fabian Gandini in the production of his last work "En la boca de la tormenta [In the mouth of the storm]". Gandini is among the first artists to develop the "non-dance" choreographic movement in Buenos Aires, the city where he has lived and worked since 2004. My purpose in this paper will be to describe and analyze Gandini's artistic practice in terms of a "Aesth-ethics of Fissure" linked not only to a poetical singularity but also to a critic of local dance productive practices. By using the temporal perception and the stilling of movement as dramaturgical resources, Gandini tends to subvert a strong legacy of expressionism. I would like to argue that his choreographic work embodies a political statement in the institutional context of Buenos Aires' contemporary dance by exposing a specific form of "performative fragility" that establishes itself at the frontier of theatrical fiction.

\section{Streszczenie}

\section{Fabian Gandini i est(etyka) pęknięcia}

W 2015 roku współpracowałem z argentyńskim choreografem Fabianem Gandinim przy realizacji jego ostatniego utworu „En la boca de la tormenta”. Jako jeden z pierwszych artystów Gandini opracował „nietaneczny” ruch choreograficzny w Buenos Aires, gdzie mieszka i pracuje od 2004 roku. Celem niniejszego artykułu jest opis i analiza działań artystycznych Gandiniego w kategoriach „est-etyki pęknięcia” powiązanej nie tylko z poetycką osobliwością, ale także z krytyką lokalnych praktyk tańca. Wykorzystując tymczasową percepcję i uspokojenie ruchu jako zasobów dramaturgicznych, Gandini dąży do obalenia wszechobecnej spuścizny ekspresjonizmu. Chciałbym dowieść, że jego działalność choreograficzna stanowi ucieleśnienie politycznej deklaracji w instytucjonalnym kontekście tańca współczesnego Buenos Aires przez ujawnienie specyficznej formy „wątłości performatywnej”, znajdującej się na granicy fikcji teatralnej. 